\author{
LOUISE NOELLE
}

\title{
Ramón Torres Martínez (1924-2008)
}

$\mathrm{P}$ ARA Un BUEN Número de habitantes de la ciudad de México y algunos de sus visitantes, la década de los años sesenta representa un momento dorado abruptamente concluido cuando llegaron las olimpiadas que resultaron empańadas por los trágicos acontecimientos del 2 de octubre. En el ámbito de la arquitectura, constituye el último periodo de la supremacía del Movimiento Moderno, aunque ya se oían voces de disidencia; era el momento en que surgían excelentes ejemplos del dominio de los materiales y de las técnicas alentados por la doctrina del "menos es más" (less is more) de Ludwig Mies van der Rohe. En ese contexto, cabe destacar el pasaje comercial Jacaranda, creado en 1959, pues sus autores alcanzaron con él una gran depuración del lenguaje arquitectónico. A este importante hecho se agrega que el pasaje se había convertido en un símbolo de la vida social de la época, pues constituía un polo de atracción para los jóvenes de la ciudad capital. ¿Quién no recuerda haber disfrutado un café en el Toulouse y una copa en La Llave de Oro, admirado las novedosas piezas de joyería de Ernesto Paulsen o comprado una prenda de vestir en sus atractivas boutiques?

Estos recuerdos, relativos tanto a la arquitectura como a los habitantes de la ciudad, fueron suscitados por la visión de dos jóvenes profesionistas que se empeñaron en participar en la vanguardia arquitectónica y en promover una nueva forma de vivir en la ciudad: Ramón Torres Martínez y Héctor Velázquez Moreno. Efectivamente, como promotores, lograron que cuatro propietarios fusionaran sus terrenos con el objeto de plantear un conjunto arquitectónico que incrementara el valor comercial de aquéllos. La propuesta consistía en ligar 


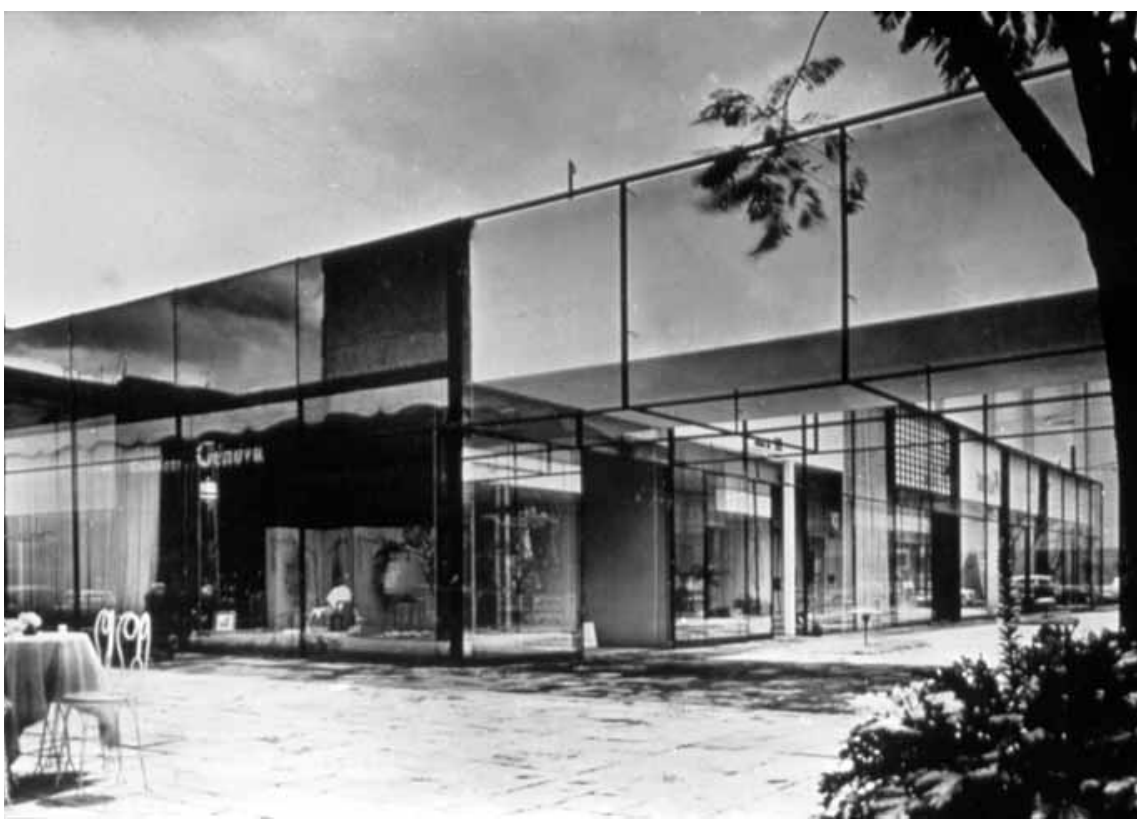

I. Ramón Torres Martínez y Héctor Velázquez Moreno, pasaje comercial Jacaranda, Zona Rosa, México D.F., I959. Foto: Guillermo Zamora.

las tres calles colindantes por medio de vías peatonales que concurrirían en una plaza central. Así, optaron por un edificio de un solo nivel, donde sería posible tener un mezzanino interior, y colocaron el estacionamiento en la azotea para optimizar el uso del predio sin detrimento del servicio a los futuros usuarios. En cuanto al novedoso lenguaje plástico, plantearon una fachada continua de cristal tras la que, a manera de telón interno, cada inquilino tenía la posibilidad de imprimir una identidad particular a su local.

El 4 de septiembre de 2008, falleció Ramón Torres Martínez, querido amigo desde hace más de tres décadas, del que siempre guardaré amables recuerdos. Su sino fue el de un arquitecto comprometido a fondo con su profesión y sobresaliente en la Universidad Nacional Autónoma de México, donde no sólo fue profesor a partir de 1952 en la entonces Escuela Nacional de Arquitectura y director de ella desde 1965 hasta 1973, pues también fue uno de los creadores de los edificios de la Ciudad Universitaria, declarada hace un año patrimonio mundial por la Unesco. 


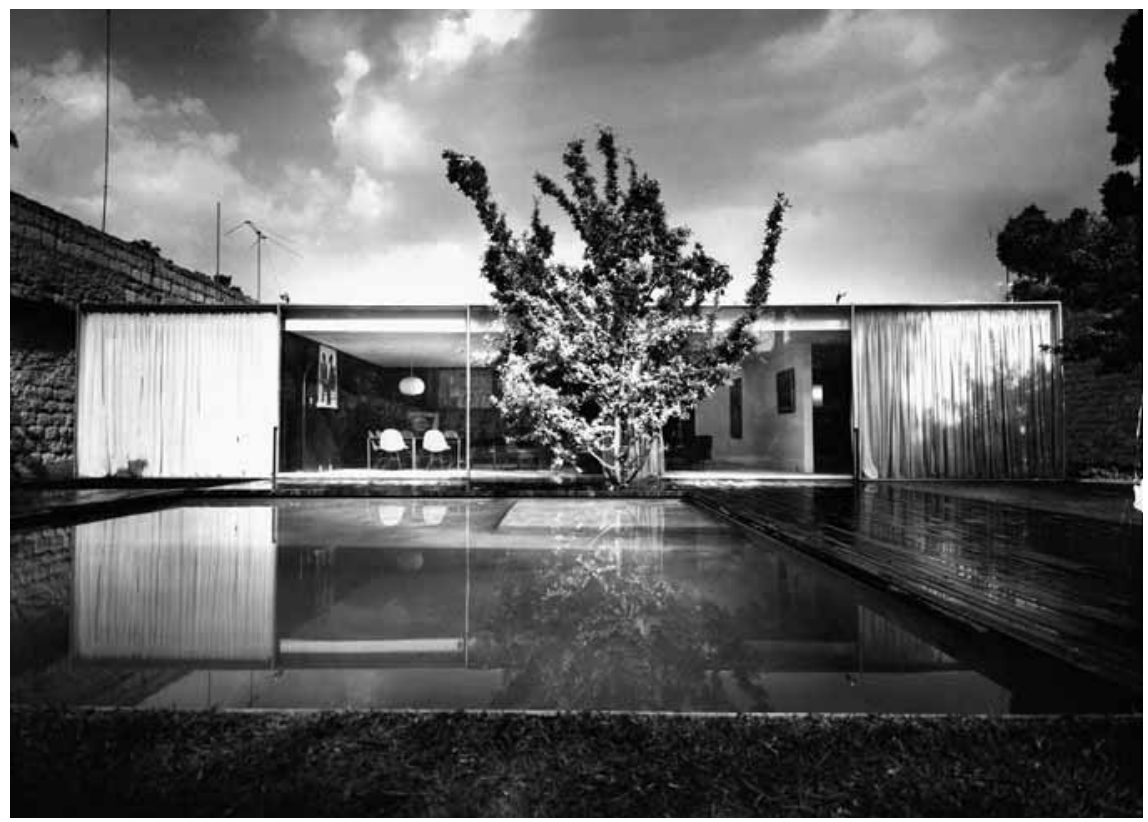

2. Ramón Torres Martínez y Héctor Velázquez Moreno, Casa Torres, San Ángel, México D.F., i962. Foto: Guillermo Zamora.

Ramón Torres nació en Pachuca, Hidalgo, el 22 de noviembre de I924, y se trasladó a la capital del país para realizar sus estudios profesionales en la Escuela Nacional de Arquitectura de la Universidad Nacional Autónoma de México, que por entonces se localizaba en el edificio que había albergado a la Academia de San Carlos en el centro de la ciudad de México. Era la época en que daban clases en esa institución los arquitectos más importantes del país, como José Villagrán García — de teoría— y Mario Pani, Enrique del Moral y Augusto H. Álvarez — de proyectos—, este último titular del taller en que Ramón Torres cursó la carrera. Su graduación como arquitecto tuvo lugar el 7 de noviembre de $1949,{ }^{\mathrm{I}}$ y poco después de esa fecha partió a cursar estudios en el Instituto de Urbanismo de París, que realizó entre 195 I y 1952. En la forma-

I. Se trata de una tesis de licenciatura realizada con Héctor Velázquez Moreno, "Planeación del reclusorio de las Islas Marías” (Universidad Nacional Autónoma de México-Escuela Nacional de Arquitectura, 7 de noviembre de 1949), que expresa su preocupación temprana por las obras de contenido social. 
ción de este joven profesionista tuvieron una influencia definitiva sus maestros universitarios, como los que ya mencionamos, a los cuales se agrega Antonio Pastrana. ${ }^{2}$ En 1954, Ramón Torres emprendió su práctica privada en sociedad con Héctor Velázquez, en lo que se puede calificar como colaboración ejemplar en su campo durante más de cuatro décadas.

Hemos señalado ya su temprana actividad en la docencia, coronada por su nombramiento como director de la Escuela de Arquitectura de nuestra magna casa de estudios. Al tomar posesión de ese cargo, después de Jorge González Reyna, continuó con la idea de su connotado predecesor de crear las instancias educativas que complementaran la carrera de arquitectura. Estableció una serie de pasos intermedios que permitieran, a quienes no podían concluir la carrera, aprovechar sus conocimientos en una actividad terminal: dibujante, topógrafo o administrador de obra. De manera paralela, propuso que se crearan la Escuela de Diseńo Industrial, que compartiría algunos cursos iniciales de diseño con Arquitectura, y la División de Estudios Superiores para ampliar los conocimientos de los egresados en las especialidades de diseño arquitectónico, urbanismo, construcción y restauración de monumentos. Finalmente, puso en marcha el Centro de Investigaciones Arquitectónicas ligado a un Centro de Información.

La obra de Ramón Torres logró una serie de aciertos que se abre en 1950 con el proyecto de la Facultad de Medicina en la flamante Ciudad Universitaria de la Universidad Nacional Autónoma de México, realizado en colaboración con Pedro Ramírez Vázquez, Roberto Álvarez Espinoza y Héctor Velázquez. $\mathrm{Al}$ respecto, es posible señalar un primer periodo en que sus obras se inscriben dentro del llamado estilo internacional, caracterizado por el uso irrestricto de cristales de piso a techo, estructuras metálicas y techumbres de concreto con voladizos. Era — señala Torres - "una época en que usábamos grandes cristales que lanzaban al exterior a los habitantes de las casas que comulgaban con este espíritu extrovertido". ${ }^{3}$ En cierta manera, la influencia de sus maestros se hace presente entonces, cuando destacan algunas obras suyas en la ciudad de México, como el edificio de apartamentos de Marsella 79, en la colonia Juárez, y el de Nazas I43, en la colonia Cuauhtémoc, construidos en 1957 y I959, res-

2. Información tomada de Louise Noelle, "Ramón Torres Martínez", en Arquitectos contemporáneos de México, México, Trillas, I989, pp. I49-152, y "Entrevista con el arquitecto Ramón Torres”, Arquitectura/México, México, núm. I I7, 1978, pp. I6-I9.

3. Noelle, "Entrevista...", op. cit., p. I6. 
pectivamente. Asimismo, la casa de campo de Cuernavaca, Morelos, de 1959, planeada en colaboración con Víctor de la Lama, resultó una residencia deslumbrante por el despliegue de un sistema constructivo que trataba de llevar al límite los materiales y las estructuras para lograr una ligereza y una transparencia extraordinarias.

En especial, cabe destacar el citado pasaje comercial Jacaranda, de 1959, de la llamada Zona Rosa, como un símbolo no sólo del trabajo de Torres y Velázquez, sino de la arquitectura mexicana toda y de un estilo de vida. Probablemente, la propia casa de Ramón Torres en San Ángel, de 1962, sea uno de los últimos ejemplos de este periodo, por sus amplios ventanales que integran la estancia al jardín y la alberca. Sin embargo, en esa obra se aprecia ya un interés incipiente por explorar y utilizar algunos materiales artesanales cuyas texturas rugosas contrastan con la lisura de los materiales industrializados, logrando con ello un ingenioso juego táctil y visual. Posteriormente, el equipo de arquitectos de Torres abandonó el camino del racionalismo a ultranza y propuso en cambio un uso más frecuente de muros hacia el exterior para lograr interiores más acogedores. Esta tendencia se aprecia sobre todo en un buen número de casas habitación proyectadas a partir de los años sesenta y localizadas en el Distrito Federal, tanto en Las Águilas como en Tetelpan. A esto se agrega una serie de casas de fines de semana construidas en Valle de Bravo y en Cancún, donde los autores tomaron muy en cuenta el entorno y el clima y aprovecharon sistemas constructivos locales.

Para Ramón Torres, "son más importantes las obras en que se trató de resolver el problema de la concentración de núcleos numerosos”, y por ello considera que "para comprender a la arquitectura en toda su extensión" ${ }^{4}$ es necesario participar en todos los niveles de la práctica profesional. Así, en 1964, con Héctor Velázquez, trabajó en el proyecto de urbanización que comprende io 000 viviendas en el conjunto habitacional San Juan de Aragón. En este mismo sentido, es importante mencionar la contribución de ambos en 1968 en la Villa Olímpica, donde el equipo formado con Agustín Hernández, Manuel González Rul y Carlos Ortega logró crear un conjunto importante y eficiente.

En este orden de ideas, casi 20 años después aquella dupla realizó los conjuntos habitacionales Nueva Imagen y Usumacinta, en Villahermosa, Tabasco, en 1984-I986. Esas obras, también de ladrillo aparente, se acometieron para atender la creciente demanda de una población urbana que crecía explosiva- 


\section{LOUISE NOELLE}

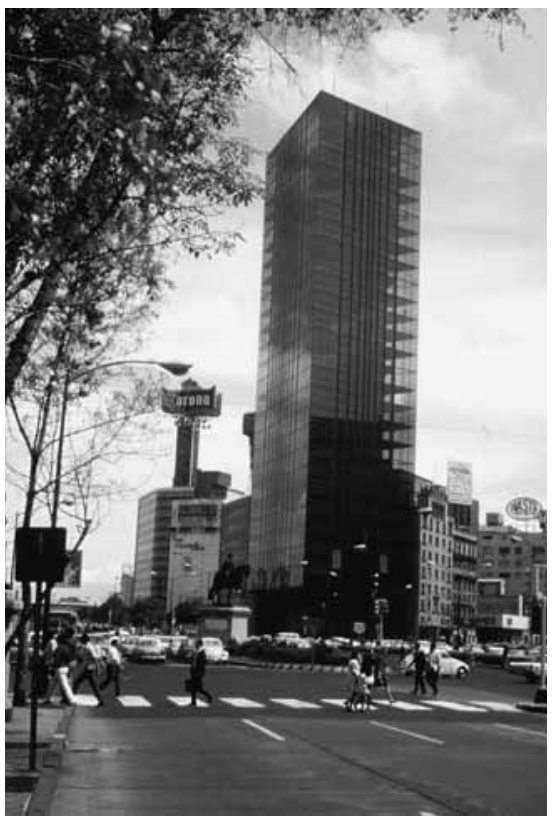

3. Ramón Torres Martínez, David Muñoz y Sergio Santacruz, edificio de la Lotería Nacional, México D.F., I97I.

Foto: Louise Noelle.

mente en esa entidad. Asimismo, en el campo de la arquitectura que intenta responder a los requerimientos sociales, podemos anotar una serie de hospitales construidos para Pemex, tanto al sur de la ciudad de México como en Salamanca, Guanajuato, y Veracruz, Veracruz, entre 1974 y 1984. A ello se agregan los proyectos para otros dos nosocomios del Instituto Mexicano del Seguro Social: el Hospital General de Zamora, Michoacán, y el Hospital Nacional Homeopático, del Distrito Federal.

No debemos olvidar una serie de edificaciones específicas con funciones especiales, como, entre 1966 y 1967, los Laboratorios Recordatti de México y el Edificio AMIME, de 1970, unos y otro en la capital. En 1974, Torres y Velázquez construyen una fábrica de refrescos y purificación de agua en Cancún, Quintana Roo. En particular, destaca también la nueva torre de la Lotería Nacional de 1971, levantada en colaboración con David Muñoz y Sergio Santacruz, tanto por la altura de su esbelto cuerpo triangular como por la novedosa cimentación conforme a un sistema criogénico. A este tipo de edificaciones específicas se agrega en 1986 el Museo de Historia Natural, localizado al borde de la laguna de las Ilusiones, en Villahermosa, Tabasco. 
En 1993, Torres erigió en Oaxaca la Casa Hernández, en colaboración con Héctor Velázquez Graham, y recientemente la Pequeña Cabaña de Chiconcuac, Morelos, en 2000, con ayuda de Olga Palacios. En 1995 y en equipo con Carmen Huesca, proyectó el edificio de Laboratorios de Investigación y Posgrado de la Facultad de Medicina, de la Universidad Nacional Autónoma de México, obra que buscó integrar al campus universitario y muy en particular a la Facultad de Medicina, por lo que se convirtió en un eslabón que cierra el ciclo de un trabajo arquitectónico vigilante y siempre renovado.

Resulta adecuado concluir estas líneas con las siguientes palabras del propio Ramón Torres:

se puede decir que la responsabilidad del arquitecto es enorme, pues tiene la obligación de darle al hombre en su entorno la dosis de belleza necesaria para su desarrollo. Por la amplitud de la arquitectura y su carácter envolvente, debe de satisfacer las necesidades físicas y estéticas de sus usuarios [...] Es indudable que el hombre debe ser la medida para toda obra arquitectónica. ${ }^{5}$

Por todo ello, podemos afirmar que nos referimos a un gran arquitecto que dedicó su vida a cultivar la pasión que sentía por la arquitectura, y que su fallecimiento resulta una dolorosa pérdida para sus muchos amigos y para la arquitectura mexicana del siglo xx. \$s 